\title{
The Reason for Discontinuation of the First Tumor Necrosis Factor (TNF) Blocking Agent Does Not Influence the Effect of a Second TNF Blocking Agent in Patients with Rheumatoid Arthritis
}

\author{
MARLIES BLOM, WIETSKE KIEVIT, JAAP FRANSEN, INA H. KUPER, ALFONS A. den BROEDER, \\ CARLA M.A. De GENDT, TIM L. JANSEN, HERMAN L.M. BRUS, MART A.F.J. van de LAAR, and PIET L.C.M. van RIEL
}

\begin{abstract}
Objective. To investigate whether the reason for discontinuation of the first tumor necrosis factor (TNF) blocking agent influences the effect of a second TNF blocking agent.

Methods. Data were used from 2 Dutch registries including patients with rheumatoid arthritis (RA) treated with TNF blocking agents. Patients were divided into 3 groups based on reason for discontinuation of the first: nonresponse, loss of response, or adverse events. The primary outcome was the change from baseline of the disease activity (by DAS28) at 6 months, corrected for the baseline DAS28 score. Secondary outcomes were the change from baseline at 3 months, EULAR response rates, and the percentages of patients who reached a DAS2 8 score $\leq 3.2$ at 3 and at 6 months.

Results. In total, 49 patients who failed due to nonresponse, 75 due to loss of response, and 73 due to adverse events were included. At 6 months, the change of DAS28 score from baseline did not differ significantly between the groups $(-0.6$ to $-1.3 ; \mathrm{p} \geq 0.173)$ and similar good and moderate response rates were found ( $12 \%$ to $18 \%, \mathrm{p} \geq 0.523$, and $34 \%$ to $55 \%, \mathrm{p} \geq 0.078$, respectively). The secondary outcomes were also comparable between the 3 groups.

Conclusion. The results of our observational study suggest that a second TNF blocking agent may be effective after failure of the first, regardless of the reason for discontinuation of the first TNF blocking agent. (First Release Sept 1 2009; J Rheumatol 2009;36:2171-7; doi:10.3899/ jrheum.090054)
\end{abstract}

Key Indexing Terms:

\section{RHEUMATOID ARTHRITIS} EFFECT
Tumor necrosis factor- $\alpha$ (TNF- $\alpha$ ) blocking agents have been shown to be efficacious in the treatment of rheumatoid arthritis (RA), with response rates up to $70 \%{ }^{1-3}$. However, $21 \%-35 \%$ of patients who started treatment with a TNF blocking agent discontinued these agents within the first

From the Department of Rheumatology, Radboud University Nijmegen Medical Centre, Nijmegen; Medisch Spectrum Twente, Enschede; Sint Maartenskliniek, Nijmegen; Rijnstate Hospital, Arnhem; Medical Centre Leeuwarden, Leeuwarden; and Twee Steden Hospital, Tilburg, The Netherlands.

Data collection for the DREAM cohort was supported by the Dutch National Health Insurance Board and the Dutch affiliations of Wyeth Pharmaceuticals, Abbott Pharmaceuticals, Schering-Plough Corporation, Roche Pharmaceuticals, and Bristol-Myers Squibb.

M. Blom, MD; W. Kievit, PhD; J. Fransen, PhD, Department of

Rheumatology, Radboud University Nijmegen Medical Centre;

H.H. Kuper, MD, PhD, Medisch Spectrum Twente; A.A. den Broeder, MD, PhD, Sint Maartenskliniek; C.M.A. De Gendt, MD, Rijnstate Hospital; T.L. Jansen, MD, PhD, Medical Centre Leeuwarden; H.L.M. Brus, MD, PhD, Twee Steden Hospital; M.A.F.J. van de Laar, MD, PhD, Professor, Medisch Spectrum Twente; P.L.C.M. van Riel, MD, PhD, Professor, Radboud University Nijmegen Medical Centre.

Address correspondence to Dr. M. Blom, Department of Rheumatology, Radboud University Nijmegen Medical Centre, PO Box 9101, H 470, 6500 HB Nijmegen, The Netherlands.E-mail:m.blom@reuma.umcn.nl Accepted for publication May 1, 2009. year due to either lack of effect or adverse events ${ }^{4-6}$. Studies have shown that a switch to a second TNF blocking agent may be beneficial in patients who failed the first ${ }^{7-15}$.

Although it seems against expectations that a patient who failed a TNF blocking agent may benefit from switching to another TNF blocking agent, there are some biochemical explanations. All 3 TNF blocking agents currently available, infliximab, adalimumab and etanercept, target TNF- $\alpha$; however, biochemical structures and properties differ. Although formation of human anti-chimeric antibodies (HACA) or human anti-human antibodies (HAHA) ${ }^{16-18}$ can lead to either secondary loss of response or adverse events, there is no indication that antibodies against one TNF blocking agent influence the effect of a second TNF blocking agent ${ }^{19}$.

On the other hand, lack of response to a TNF blocking agent may be caused by genetic variation within the TNFA gene or other candidate genes within the TNF- $\alpha$ pathway ${ }^{20,21}$. Taking this underlying mechanism into account, it is conceivable that a patient who showed no response to the first TNF blocking agent will also fail to respond to a second TNF blocking agent. Therefore, the reason for discontinuation of the first TNF blocking agent, in this case non-

Personal non-commercial use only. The Journal of Rheumatology Copyright $\subset$ $~ 2009$. All rights reserved. 
response, may be a reason not to switch to a second TNF blocking agent.

The aim of our study was therefore to investigate whether the reason for discontinuation of the first TNF blocking agent influences the effect of treatment with a second TNF blocking agent.

\section{MATERIALS AND METHODS}

Patients. Data from 2 registries were used: the local registry of the Radboud University Nijmegen Medical Centre, which was started in 1997, including patients with RA who started treatment with a TNF blocking agent in daily clinical practice at the university hospital; and the Dutch RhEumatoid Arthritis Monitoring (DREAM) registry, which started in February 2003. In the latter, data were collected from RA patients treated with TNF blocking agents at 11 hospitals ${ }^{22}$. At the time of the analysis, the local registry contained complete data until July 2006 and the DREAM registry until December 2007. Both registries had similar inclusion criteria and data collection. Therefore, data could be combined for the analyses. All patients fulfilled the 1987 American College of Rheumatology (ACR) criteria for $\mathrm{RA}^{23}$. Patients of both cohorts also satisfied the Dutch criteria for reimbursement for treatment with a TNF blocking agent: moderate to high disease activity [Disease Activity Score for 28 joints (DAS28) $\geq 3.2$ ]; and failure of at least 2 disease modifying antirheumatic drugs (DMARD) including optimal doses of methotrexate ( $25 \mathrm{mg}$ per wk).

The study protocol was submitted to the ethics committee. Since both registers contained data from daily clinical practice, the ethics committee determined that no ethical approval was required.

For the analysis, patients were retrospectively divided into 3 groups by reason for discontinuation of the first TNF blocking agent. The first group, the nonresponders, consisted of patients who failed due to lack of effect according to their attending rheumatologist and who showed no good or moderate response using the European League Against Rheumatism (EULAR) response criteria ${ }^{24}$ based on the best DAS28 score during the total time of use of the first TNF blocking agent. The second group included patients who failed the first TNF blocking agent due to secondary loss of response after initial good or moderate EULAR response, based on the best DAS28 score during the total time of use of the first TNF blocking agent. The third group consisted of patients who failed the first TNF blocking agent due to adverse events. If both lack of effect and adverse events were reported as the reason for discontinuation of the first TNF blocking agent by the rheumatologist, we considered lack of effect as the main reason for discontinuation.

Treatment. The choice of the TNF blocking agent and the dosing scheme were at the discretion of the attending rheumatologist. In general, patients started with TNF blocking agents following Dutch labeled doses: infliximab $3 \mathrm{mg} / \mathrm{kg}$ given intravenously every 8 weeks after a loading dose at Week 0,2 , and 6; etanercept $25 \mathrm{mg}$ subcutaneously twice weekly; or adalimumab $40 \mathrm{mg}$ subcutaneously every 2 weeks. Treatment with a TNF blocking agent could be combined with DMARD and/or corticosteroids. Start and stop dates, doses, and reasons for changes were recorded.

Outcomes. Baseline characteristics were registered at the start of the second TNF blocking agent, including age, sex, disease duration, number of previous DMARD, and rheumatoid factor status. A trained study nurse (both registries) or the attending rheumatologist (at the local registry) assessed patients at the start of the first TNF blocking agent and every 3 months thereafter. A switch to the next TNF blocking agent could be made at any time, that is, irrespective of the timing of the clinical assessments. The assessments included tender and swollen joint counts (TJC and SJC), erythrocyte sedimentation rates (ESR), and the visual analog scale for general health (VASGH). The DAS28 was calculated to evaluate disease activity ${ }^{25}$. For the analyses, assessments were used from baseline $(>-3$ and $\leq 0$ months), 3 (> 1.5 and $\leq 4.5$ months), and 6 months ( $>4.5$ and $\leq 7.5$ months). In case of missing DAS28 scores caused by a missing value for the ESR, the ESR was imputed by means of linear multivariate regression using the patient's values for TJC, SJC, and VASGH.

The primary outcome was the change from baseline in DAS28 after 6 months of the second TNF blocking agent. Secondary outcomes were the change from baseline in DAS28 at 3 months; the EULAR response rates (good and moderate) at 3 and 6 months; the percentages of patients who reached a DAS28 $\leq 3.2$ at 3 and 6 months; and the drug survival of the second TNF blocking agent.

Analyses. Data for all patients who started a second TNF blocking agent prior to January 2006 (hospital registry) or June 2007 (DREAM registry) were selected for analysis. January 2006 and June 2007 were chosen so that all patients had at least 6 months of followup at the time of the analyses. Analyses were performed per protocol so that the results represent daily clinical practice.

Baseline characteristics were expressed as mean (SD) or as median (range) as appropriate and compared between the 3 groups using Pearson's chi-square test for categorical data and one-way ANOVA or the nonparametric Kruskal-Wallis test for continuous data. The primary outcome, the change from baseline in DAS28 score at 6 months, was compared between the groups using multiple linear regression analysis with correction for disease activity and use of corticosteroids at baseline. This method was also used to compare the change from baseline at 3 months between the groups. The change from baseline at 3 and 6 months within the 3 groups was analyzed using the paired Student $t$ test. The response rates and percentages of patients who reached a DAS28 score $\leq 3.2$ were compared between the groups by the Pearson chi-square test. Kaplan-Meier survival analysis was used to assess drug survival and the log-rank test was used to compare the survival curves. To correct for multiple comparisons, a Bonferroni correction was performed and an adjusted $\alpha$ of $0.017(0.05 / 3)$ was considered significant.

Analyses were performed using SPSS version 14.0 (SPSS Inc., Chicago, IL, USA).

\section{RESULTS}

Baseline characteristics. A total of 245 patients with RA were identified who failed a first TNF blocking agent and were switched to a second prior to January 2006 (hospital registry) or June 2007 (DREAM registry). Of these patients, $20(8 \%)$ were excluded since they discontinued the first TNF blocking agent due to reasons other than lack of effect or adverse events, such as wish to go into pregnancy, need for surgery, or discontinuation by patient's own initiative. Of the remaining 225 patients, 197 (88\%) had complete data, with a baseline DAS28 and a best DAS28 score during treatment with the first TNF blocking agent. These patients were classified into 3 groups: 49 nonresponders, 75 patients who failed due to loss of response, and 73 who failed due to adverse events. The median time intervals to achieve the best DAS28 score during use of the first TNF blocking agent in nonresponders, in patients who failed due to loss of response, and in those who failed due to adverse events was 2.2 months (range $0-11.5), 5.5$ months (0.8-34.1), and 2.8 months $(0-15.2)$, respectively $(\mathrm{p}<0.0001)$.

Table 1 shows patients' baseline characteristics. No differences were observed between the groups regarding sex, age, disease duration, rheumatoid factor status, and number of previous DMARD. Infliximab was used more frequently $(p=0.010)$ as the first TNF blocking agent in patients who failed due to adverse events compared to the other 2 groups.

Personal non-commercial use only. The Journal of Rheumatology Copyright @ 2009 . All rights reserved. 
Table 1. Patients' baseline characteristics.

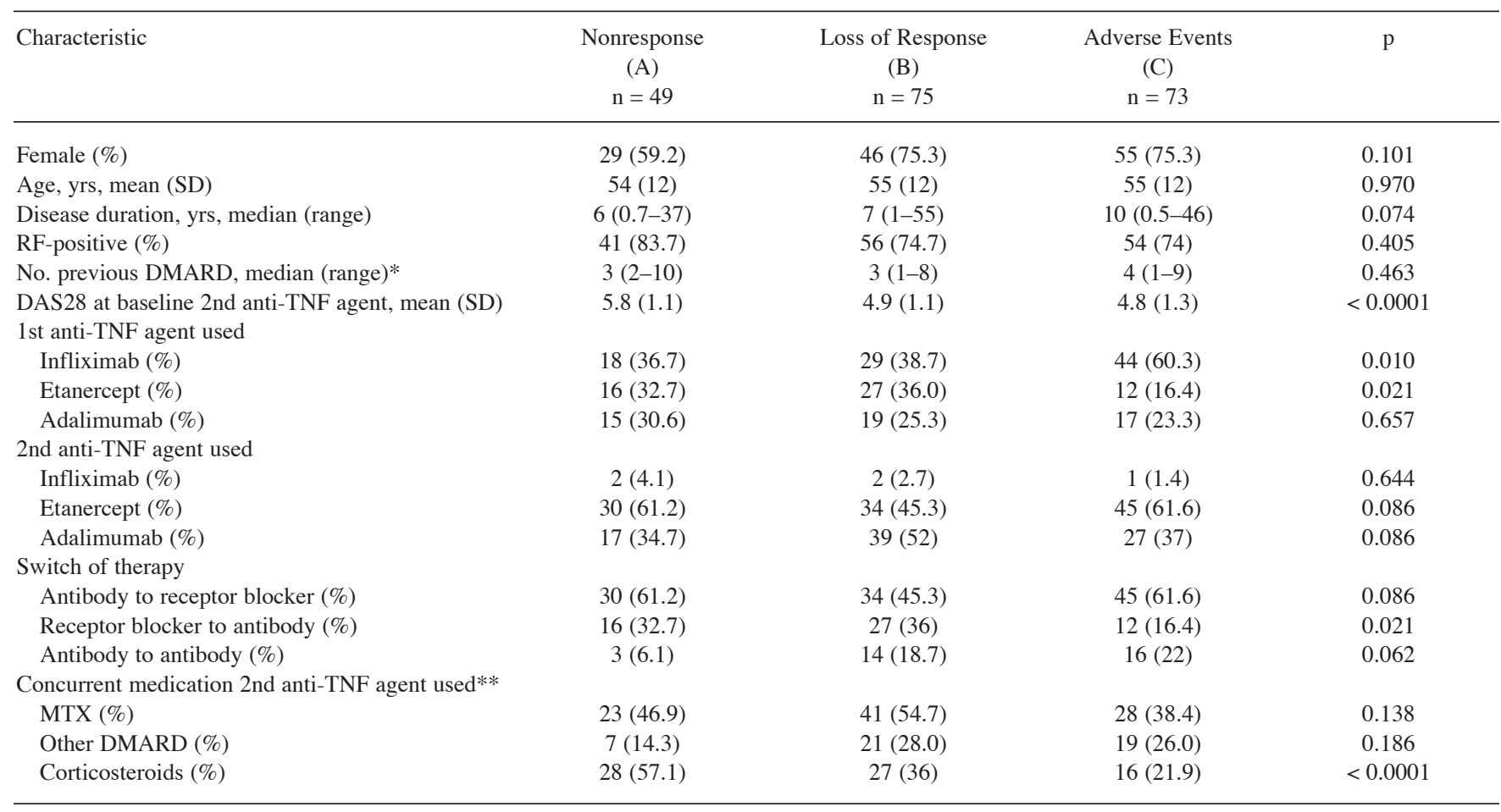

* Missing data in 2\% (1/49) in A. ** Missing data in A, B, and C, 14\% (7/49), 9\% (7/75), and 16\% (12/73), respectively. RF: rheumatoid factor; DMARD: disease modifying antirheumatic drugs; TNF: tumor necrosis factor; MTX: methotrexate.

All patients had active disease at the start of the second TNF blocking agent. However, disease activity was significantly higher in the nonresponders compared to the patients who failed due to loss of response and those who failed due to adverse events $(p<0.0001)$. In addition, nonresponders received oral corticosteroids more frequently as concomitant therapy than the other 2 groups $(\mathrm{p}<0.0001)$. Patients who failed due to adverse events switched less frequently from a receptor blocker to a monoclonal antibody than the patients who failed due to loss of response $(\mathrm{p}=0.007)$.

At 3 and 6 months, 4\% (2/49) and 12\% (6/49) of the nonresponders, $7 \%(5 / 75)$ and $21 \%(16 / 75)$ of patients who failed due to loss of response, and $11 \%(8 / 73)$ and $23 \%$ (17/73) of patients who failed due to adverse events had discontinued the second TNF blocking agent. Table 2 shows the reasons for discontinuation in these patients. These patients were not taken into account in the analyses of the effect of the second TNF blocking agent at these timepoints, according to the per-protocol analysis.

Effects of the second TNF blocking agent. Figure 1 shows the mean DAS28 scores at baseline, at 3 and 6 months, and at the time of discontinuation of the first TNF blocking agent, and at baseline and 3 and 6 months of the second agent. At 3 and 6 months after the start of the second TNF blocking agent, the DAS28 scores did not differ between the 3 groups.

Results of analyses of the primary and secondary out-
Table 2. Reasons for discontinuation of the second TNF blocking agent at 3 and 6 months and the total followup time.

\begin{tabular}{|c|c|c|c|}
\hline Timepoint & $\begin{array}{c}\text { Nonresponse } \\
\qquad \begin{array}{c}\text { (A) } \\
n=49\end{array}\end{array}$ & $\begin{array}{c}\text { Loss of Response } \\
\begin{array}{c}\text { (B) } \\
n=75\end{array}\end{array}$ & $\begin{array}{c}\text { Adverse Events } \\
\text { (C) } \\
n=73\end{array}$ \\
\hline \multicolumn{4}{|l|}{3 months } \\
\hline Lack of effect (\%) & - & $2 / 5(40)$ & $1 / 8(13)$ \\
\hline Adverse events (\%) & $2 / 2(100)$ & $3 / 5(60)$ & $7 / 8(88)$ \\
\hline Other $(\%)$ & - & - & - \\
\hline \multicolumn{4}{|l|}{6 months } \\
\hline Lack of effect (\%) & $4 / 6(67)$ & $10 / 16(63)$ & 4/17 (24) \\
\hline Adverse events (\%) & $2 / 6(33)$ & $6 / 16(38)$ & $12 / 17(71)$ \\
\hline Other $(\%)^{*}$ & - & - & $1 / 17(6)$ \\
\hline \multicolumn{4}{|l|}{ Total followup time } \\
\hline Lack of effect (\%) & $13 / 20(65)$ & $20 / 30(67)$ & $7 / 26(27)$ \\
\hline Adverse events (\%) & $5 / 20(25)$ & $9 / 30(30)$ & $15 / 26(58)$ \\
\hline Other $(\%)^{* *}$ & $2 / 20(10)$ & $1 / 30(3)$ & $4 / 26(15)$ \\
\hline
\end{tabular}

* Patient's own initiative. ** In group A 1 patient died and 1 patient discontinued due to planned surgery; in group B 1 patient discontinued because of wish for pregnancy; in group $\mathrm{C} 3$ patients discontinued on their own initiative and 1 patient was lost to followup.

comes are shown in Table 3. At 6 months, the disease activity improved significantly in all 3 groups (between -0.6 and $-1.3 ; \mathrm{p} \leq 0.005)$. After the correction for disease activity and use of corticosteroids at baseline, this improvement did not differ between the groups. Similar results were found for the DAS28 at 3 months. The response rates were also compara- 


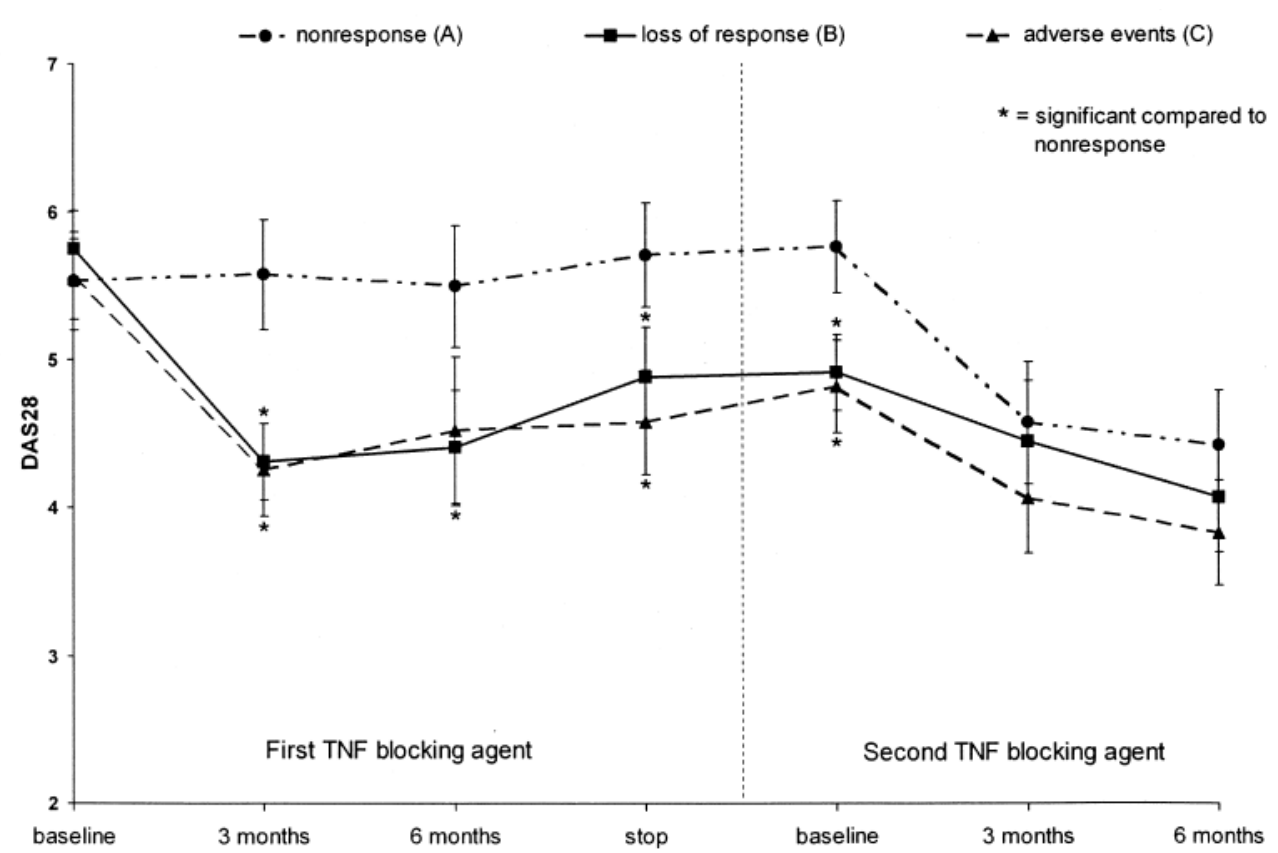

Figure 1. Mean DAS28 scores (95\% CI) during use of the first and second TNF blocking agents. Time to stopping the first TNF blocking agent: median 3 months (range 1-20) for the nonresponders, 12 months (3-62) for patients who failed due to loss of response, and 6 months $(0-29)$ for patients who failed due to adverse events $(\mathrm{p}<0.0001)$. *Significant compared to nonresponse.

Table 3. Effects of the second TNF blocking agent. Values are means (standard deviation) unless stated otherwise.

\begin{tabular}{|c|c|c|c|c|c|c|}
\hline Outcomes & $\begin{array}{c}\text { Nonresponse } \\
\text { (A) } \\
n=49\end{array}$ & $\begin{array}{c}\text { Loss of Response } \\
\begin{array}{c}\text { (B) } \\
n=75\end{array}\end{array}$ & $\begin{array}{c}\text { Adverse Events } \\
\text { (C) } \\
\mathrm{n}=73\end{array}$ & $\begin{array}{c}\mathrm{p}, \\
\mathrm{A} \text { vs B }\end{array}$ & $\begin{array}{c}\mathrm{p}, \\
\mathrm{A} \text { vs C }\end{array}$ & $\begin{array}{c}\mathrm{p}, \\
\mathrm{B} \text { vs C }\end{array}$ \\
\hline Change of DAS28 at 6 mo & $-1.3(1.3)$ & $-0.6(1.3)$ & $-1.0(1.4)$ & $0.965^{*}$ & $0.219 *$ & $0.173^{*}$ \\
\hline \multicolumn{7}{|l|}{ Secondary outcomes } \\
\hline Change of DAS28 at 3 mo & $-1.2(1.0)$ & $-0.7(1.3)$ & $-0.8(1.4)$ & $0.901 *$ & $0.608 *$ & $0.499 *$ \\
\hline Moderate (\%) & $18 / 44(41)$ & $13 / 38(34)$ & $14 / 46(30)$ & 0.533 & 0.299 & 0.712 \\
\hline DAS28 at $3 \mathrm{mo} \leq 3.2(\%)$ & $8 / 44(18)$ & $7 / 44(16)$ & $13 / 49(27)$ & 0.777 & 0.336 & 0.213 \\
\hline \multicolumn{7}{|l|}{ Response at $6 \mathrm{mo}$} \\
\hline Good $(\%)$ & $4 / 33(12)$ & $7 / 41(17)$ & $7 / 40(18)$ & 0.552 & 0.523 & 0.959 \\
\hline Moderate (\%) & $18 / 33(55)$ & $14 / 41(34)$ & $14 / 40(35)$ & 0.078 & 0.094 & 0.936 \\
\hline DAS28 at $6 \mathrm{mo} \leq 3.2(\%)$ & $5 / 33(15)$ & $11 / 41(27)$ & $11 / 43(26)$ & 0.225 & 0.269 & 0.897 \\
\hline
\end{tabular}

* Based on the multiple linear regression analyses in which the raw data were corrected for difference between the groups in DAS28 at baseline and use of corticosteroids. DAS28 scores were missing at baseline, at 3 or 6 months of the second TNF blocking agent in, respectively, 2\% (1/49), 6\% (3/47), and 23\% $(10 / 43)$ of $\mathrm{A}$; in $9 \%$ (7/75), 37\% (26/70), and 32\% (18/57) of B; and in 12\% (9/73), 25\% (16/65), and 23\% (13/56) of C. Improvement in DAS28 score and response rates could not be calculated due to missing values at baseline and/or at 3 or 6 months in, respectively, 6\% (3/47) and 23\% (10/43) of A; in 46\% (32/70) and 28\% (16/57) of B; and in 29\% (19/65) and 29\% (16/56) of C. DAS28: Disease Activity Score 28 joints.

ble between the 3 groups at 3 and 6 months. No differences were observed between the groups regarding the percentages of patients who reached a DAS28 score $\leq 3.2$.

Drug survival did not differ between the 3 groups (log-rank $\mathrm{p}=0.630$; Figure 2). By July 2006 (hospital registry) and December 2007 (DREAM registry), 76 (39\%) patients had discontinued the second TNF blocking agent after a median duration of use of 5.1 months (range 0.1-33.3). Table 2 also shows the reasons for discontinuation for each group after the total followup period. Patients who discontinued the first TNF blocking agent due to nonresponse or loss of response discontinued the second TNF 


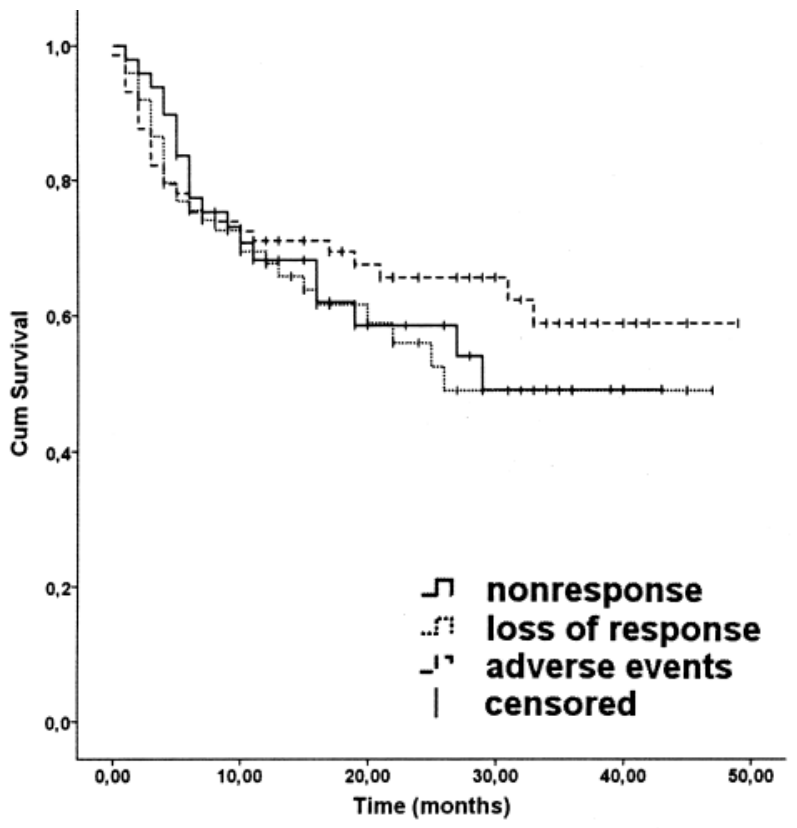

Figure 2. Drug survival of the second TNF blocking agent.

blocking agent more frequently due to lack of response; and patients who failed the first TNF blocking agent due to adverse events also failed the second more often due to adverse events $(\mathrm{p}=0.003)$.

\section{DISCUSSION}

Our aim was to investigate whether the reason for discontinuation of the first TNF blocking agent influences the effect of a second TNF blocking agent. The results showed improvement of the DAS28 score at 6 months from baseline of -0.6 to -1.3 and improvement of response rates from $51 \%$ to $67 \%$, without significant differences between patients who failed the first TNF blocking agent due to nonresponse, loss of response, or adverse events. It is noteworthy, however, that the mean disease activity remained moderate during the study period in all groups. As well, the reason for discontinuation of the first TNF blocking agent was related to the reason for discontinuation of the second. However, overall, the results suggest that a second TNF blocking agent may be effective after failure of the first agent regardless of the reason for discontinuation of the first agent.

Our observations on the effect of the second TNF blocking agent are comparable to those of previous studies in which it was concluded that a switch to a second agent can be effective $e^{7-15}$. However, previous studies found conflicting results with regard to particular groups of patients who may benefit most from a switch to a second TNF blocking agent when classified by reason for discontinuation of the first agent ${ }^{7}$. For instance, a higher response rate to etanercept was suggested in patients who were nonresponders to infliximab compared to the patients who discontinued due to loss of response ${ }^{14}$. On the other hand, a switch to adalimumab after nonresponse with infliximab was shown to be less effective than a switch to adalimumab after failure due to loss of response ${ }^{26}$. Further, the drug survival and EULAR response rate of the second TNF blocking agent were better in patients who discontinued the first agent due to adverse events than in those who switched due to lack of effect ${ }^{12,27}$. However, when response was assessed by the ACR criteria, no differences were observed ${ }^{27}$. Because of these conflicting results, no group of patients can be identified who may benefit most from a switch to a second TNF blocking agent classified by the reason for discontinuation from the first agent. This is confirmed by our results, as we found no differences in effect of the second TNF blocking agent among the 3 reasons for discontinuation of the first agent: nonresponse, loss of response, or adverse events.

In contrast to the findings that the effect of the second TNF blocking agent after failure of the first was similar among the 3 groups by reason for discontinuation, we observed that the reason for discontinuation of the first agent was related to the reason for discontinuation of the second. This is in agreement with the results of a study by Hyrich, et $a l^{28}$. However, we emphasize that drug survival and reason for discontinuation may be influenced by many factors besides the actual effect of therapy, including availability of other drugs and patient and doctor preferences and expectations. Therefore, we consider the results of the analyses on effect and response to therapy more valid.

In addition to the 3 reasons for discontinuation of first TNF blocking agent used in our study, Van Vollenhoven proposed a fourth reason: partial response ${ }^{29}$. This group is defined as patients who showed only moderate response to the first TNF blocking agent, with continuing moderately active disease. In these patients, a switch to a second TNF blocking agent would be useful only if a low level of disease activity could be achieved. In our study, the patient group who failed due to loss of response was a combination of patients who actually failed due to loss of response and of partial responders. The power of our study was too limited to compare the outcome of a second TNF blocking agent between these 2 subgroups.

Our study had some limitations. First, the classification of the 3 groups by reason for discontinuation of first TNF blocking agent was dependent on the main reason reported by the attending rheumatologist. If the reason to discontinue the first agents was "a combination of lack of effect and adverse events," for our study patients were classified as "discontinuing because of lack of effect." In this group of patients, neither of these 2 reasons was the major reason to discontinue, but merely a general dissatisfaction with the effect of therapy. We assume that adverse events were mild and acceptable until the time of discontinuation; otherwise patients would have discontinued treatment earlier due to

Personal non-commercial use only. The Journal of Rheumatology Copyright @ 2009 . All rights reserved. 
the adverse events. The additional lack of effect was the reason patients eventually discontinued therapy. This was the case in $10 \%(5 / 49)$ of the patients who were classified as nonresponders, and in only 5\% (4/75) of the patients who failed due to loss of response. Considering these low percentages, we assume that our conclusions were not influenced by misclassification. Further, the observational design of the study had advantages and disadvantages. The results closely reflect the effect of TNF blocking agents in daily clinical practice. On the other hand, the percentage of missing data is considerable. The most favorable study design to investigate the outcome of a switch between TNF blocking agents would be a randomized placebo-controlled trial directly comparing patients who switch to a second TNF blocking agent with patients who continue the first. However, such a trial would not be ethical, since continuing treatment in a patient who has shown adverse events or no response to therapy would not be justifiable.

As noted in the introduction, there is no indication that HACA or HAHA formation during treatment with the first TNF blocking agent may influence the effect of a second agent ${ }^{19}$. Although HACA and HAHA were not measured in our study, our results from epidemiological analyses seem to support this assumption. If the presence of HACA or HAHA influenced the effect of the second TNF blocking agent, no effect of the second TNF blocking agent would be expected. However, in patients who discontinued the first TNF blocking agent due to either lack of effect or adverse events, the second agent was effective. In addition, we hypothesized that differences in response to TNF blocking agents among RA patients could be related to genetic variation within the TNFA gene or other candidate genes within the TNF- $\alpha$ pathway, especially in those patients who failed the first TNF blocking agent due to primary nonresponse. Against our expectations, our data showed that a switch to a second TNF blocking agent was effective even in this group of patients. Since all 3 TNF blocking agents currently available differ in biochemical structures and properties, it is therefore conceivable that genetic variation in the binding site of one of the agents may not influence the effect of another agent using another binding site ${ }^{30-32}$. To investigate the effect of switching agents, it would be interesting to compare switching between a monoclonal antibody and a receptor blocker with the effect of switch between 2 monoclonal antibodies for each reason for discontinuation of the first TNF blocking agent. However, in our study, the patient numbers for each group were too limited for these analyses.

The goals of treatment in RA are to achieve remission, to prevent joint damage, and to maintain full function. In our study, only $15 \%-27 \%$ of the patients achieved low disease activity (DAS28 $\leq 3.2$ ) after 6 months of treatment with the second TNF blocking agent. The question arises whether a switch to a biologic with another mechanism of action, such as B cell-depleting (rituximab) or costimulation-blocking therapy (abatacept), may be more effective in reaching this goal instead of a switch to a second TNF blocking agent. To date, there has been only one observational study looking into switching to rituximab versus switching to another TNF blocking agent. That study showed that switching to rituximab was more effective than switching to another TNF blocking agent ${ }^{33}$. More research is needed to compare the various treatment options in patients who have failed TNF blocking therapy.

The results of our observational study suggest that a second TNF blocking agent may be effective after failure of the first agent regardless of the reason for discontinuation of the first. In daily clinical practice, the reason for discontinuation of the first TNF blocking agent therefore cannot be used to identify a group of patients who may benefit most, or who will not benefit, from a switch to a second TNF blocking agent after failure of the first TNF blocking agent.

\section{ACKNOWLEDGMENT}

We are indebted to all research nurses and rheumatologists of the 11 departments of rheumatology for their participation and contribution to the data collection. We acknowledge T. van Gaalen, L. Schalkwijk and C. Versteegden for the data processing, H. Groenewoud for assistance in managing the database, and Dr. M. Creemers and Dr. A. van Ede for training the research nurses in assessing joint counts.

\section{REFERENCES}

1. Maini R, St. Clair EW, Breedveld F, Furst D, Kalden J, Weisman M, et al. Infliximab (chimeric anti-tumour necrosis factor alpha monoclonal antibody) versus placebo in rheumatoid arthritis patients receiving concomitant methotrexate: a randomised phase III trial. Lancet 1999;354:1932-9.

2. Klareskog L, van der Heijde D, de Jager JP, Gough A, Kalden J, Malaise M, et al. Therapeutic effect of the combination of etanercept and methotrexate compared with each treatment alone in patients with rheumatoid arthritis: double-blind randomised controlled trial. Lancet 2004;363:675-81.

3. Keystone EC, Kavanaugh AF, Sharp JT, Tannenbaum H, Hua Y, Teoh LS, et al. Radiographic, clinical, and functional outcomes of treatment with adalimumab (a human anti-tumor necrosis factor monoclonal antibody) in patients with active rheumatoid arthritis receiving concomitant methotrexate therapy - A randomized, placebo-controlled, 52-week trial. Arthritis Rheum 2004;50:1400-11.

4. Flendrie M, Creemers MC, Welsing PM, den Broeder AA, van Riel PL. Survival during treatment with tumour necrosis factor blocking agents in rheumatoid arthritis. Ann Rheum Dis 2003;62 Suppl 2:ii30-ii33.

5. Geborek P, Crnkic M, Petersson IF, Saxne T. Etanercept, infliximab, and leflunomide in established rheumatoid arthritis: clinical experience using a structured follow up programme in southern Sweden. Ann Rheum Dis 2002;61:793-8.

6. Zink A, Listing J, Kary S, Ramlau P, Stoyanova-Scholz M, Babinsky K, et al. Treatment continuation in patients receiving biological agents or conventional DMARD therapy. Ann Rheum Dis 2005;64:1274-9.

7. van Vollenhoven R, Harju A, Brannemark S, Klareskog L. Treatment with infliximab (Remicade) when etanercept (Enbrel) has failed or vice versa: data from the STURE registry showing that switching tumour necrosis factor alpha blockers can make sense. Ann Rheum Dis 2003;62:1195-8.

Personal non-commercial use only. The Journal of Rheumatology Copyright @ 2009 . All rights reserved. 
8. Haraoui B, Keystone EC, Thorne JC, Pope JE, Chen I, Asare CG, et al. Clinical outcomes of patients with rheumatoid arthritis after switching from infliximab to etanercept. J Rheumatol 2004;31:2356-9.

9. Wick MC, Ernestam S, Lindblad S, Bratt J, Klareskog L, van Vollenhoven RF. Adalimumab (Humira ${ }^{\circledR}$ ) restores clinical response in patients with secondary loss of efficacy from infliximab $\left(\right.$ Remicade $^{\circledR}$ ) or etanercept $\left(\right.$ Enbrel $\left.^{\circledR}\right)$ : results from the STURE registry at Karolinska University Hospital. Scand J Rheumatol 2005;34:353-8.

10. Cohen G, Courvoisier N, Cohen JD, Zaltni S, Sany J, Combe B. The efficiency of switching from infliximab to etanercept and vice-versa in patients with rheumatoid arthritis. Clin Exp Rheumatol 2005;23:795-800.

11. Solau-Gervais E, Laxenaire N, Cortet B, Dubucquoi S, Duquesnoy B, Flipo RM. Lack of efficacy of a third tumour necrosis factor alpha antagonist after failure of a soluble receptor and a monoclonal antibody. Rheumatology 2006;45:1121-4.

12. Gomez-Reino JJ, Carmona L; BIOBADASER Group. Switching TNF antagonists in patients with chronic arthritis: an observational study of 488 patients over a four-year period. Arthritis Res Ther 2006;8:R29.

13. Nikas SN, Voulgari PV, Alamanos Y, Papadopoulos CG, Venetsanopoulou AI, Georgiadis AN, et al. Efficacy and safety of switching from infliximab to adalimumab: a comparative controlled study. Ann Rheum Dis 2006;65:257-60.

14. Buch MH, Bingham SJ, Bejarano V, Bryer D, White J, Reece R, et al. Therapy of patients with rheumatoid arthritis: outcome of infliximab failures switched to etanercept. Arthritis Rheum 2007;57:448-53.

15. Hjardem E, Ostergaard M, Podenphant J, Tarp U, Andersen LS, Bing J, et al. Do rheumatoid arthritis patients in clinical practice benefit from switching from infliximab to a second tumor necrosis factor alpha inhibitor? Ann Rheum Dis 2007;66:1184-9.

16. Wolbink GJ, Vis M, Lems W, Voskuyl AE, de Groot E, Nurmohamed MT, et al. Development of antiinfliximab antibodies and relationship to clinical response in patients with rheumatoid arthritis. Arthritis Rheum 2006;54:711-5.

17. Bartelds GM, Wijbrandts CA, Nurmohamed MT, Stapel S, Lems WF, Aarden L, et al. Clinical response to adalimumab: relationship to anti-adalimumab antibodies and serum adalimumab concentrations in rheumatoid arthritis. Ann Rheum Dis 2007;66:921-6.

18. Bendtzen K, Geborek P, Svenson M, Larsson L, Kapetanovic MC, Saxne T. Individualized monitoring of drug bioavailability and immunogenicity in rheumatoid arthritis patients treated with the tumor necrosis factor alpha inhibitor infliximab. Arthritis Rheum 2006;54:3782-9.

19. van der Bijl AE, Breedveld FC, Antoni CE, Kalden JR, Kary S, Burmester GR, et al. An open-label pilot study of the effectiveness of adalimumab in patients with rheumatoid arthritis and previous infliximab treatment: relationship to reasons for failure and anti-infliximab antibody status. Clin Rheumatol 2008;27:1021-8.

20. Coenen MJ, Toonen EJ, Scheffer H, Radstake TR, Barrera P, Franke B. Pharmacogenetics of anti-TNF treatment in patients with rheumatoid arthritis. Pharmacogenomics 2007;8:761-73.
21. Kooloos WM, de Jong DJ, Huizinga TW, Guchelaar HJ. Potential role of pharmacogenetics in anti-TNF treatment of rheumatoid arthritis and Crohn's disease. Drug Discov Today 2007;12:125-31.

22. Kievit W, Fransen J, Adang EM, Kuper HH, Jansen TL, De Gendt $\mathrm{CM}$, et al. Evaluating guidelines of continuation of anti-tumour necrosis factor treatment after 3 months: clinical effectiveness and costs of observed care and different alternative strategies. Ann Rheum Dis 2009;68:844-9.

23. Arnett FC, Edworthy SM, Bloch DA, McShane DJ, Fries JF, Cooper NS, et al. The American Rheumatism Association 1987 revised criteria for the classification of rheumatoid arthritis. Arthritis Rheum 1988;31:315-24

24. van Gestel AM, Prevoo ML, van 't Hof MA, van Rijswijk MH, van de Putte LB, van Riel PL. Development and validation of the European League Against Rheumatism response criteria for rheumatoid arthritis. Comparison with the preliminary American College of Rheumatology and the World Health Organization/ International League Against Rheumatism criteria. Arthritis Rheum 1996;39:34-40.

25. Prevoo ML, van 't Hof MA, Kuper HH, van Leeuwen MA, van de Putte LB, van Riel PL. Modified disease activity scores that include twenty-eight-joint counts. Development and validation in a prospective longitudinal study of patients with rheumatoid arthritis. Arthritis Rheum 1995;38:44-8.

26. Bennett AN, Peterson P, Zain A, Grumley J, Panayi G, Kirkham B. Adalimumab in clinical practice. Outcome in 70 rheumatoid arthritis patients, including comparison of patients with and without previous anti-TNF exposure. Rheumatology 2005;44:1026-31.

27. Karlsson JA, Kristensen LE, Kapetanovic MC, Gulfe A, Saxne T, Geborek P. Treatment response to a second or third TNF-inhibitor in RA: results from the South Swedish Arthritis Treatment Group Register. Rheumatology 2008;47:507-13.

28. Hyrich KL, Lunt M, Watson KD, Symmons DP, Silman AJ. Outcomes after switching from one anti-tumor necrosis factor alpha agent to a second anti-tumor necrosis factor alpha agent in patients with rheumatoid arthritis: results from a large UK national cohort study. Arthritis Rheum 2007;56:13-20.

29. van Vollenhoven RF. Switching between anti-tumour necrosis factors: trying to get a handle on a complex issue. Ann Rheum Dis 2007;66:849-51.

30. Lee YH, Ji JD, Song GG. Tumor necrosis factor-alpha promoter $-308 \mathrm{~A} / \mathrm{G}$ polymorphism and rheumatoid arthritis susceptibility: a metaanalysis. J Rheumatol 2007;34:43-9.

31. Padyukov L, Lampa J, Heimburger M, Ernestam S, Cederholm T, Lundkvist I, et al. Genetic markers for the efficacy of tumour necrosis factor blocking therapy in rheumatoid arthritis. Ann Rheum Dis 2003;62:526-9.

32. Kastbom A, Bratt J, Ernestam S, Lampa J, Padyukov L, Soderkvist $\mathrm{P}$, et al. Fc-gamma receptor type IIIA genotype and response to tumor necrosis factor alpha-blocking agents in patients with rheumatoid arthritis. Arthritis Rheum 2007;56:448-52.

33. Finckh A, Ciurea A, Brulhart L, Kyburz D, Moller B, Dehler S, et al. B cell depletion may be more effective than switching to an alternative anti-tumor necrosis factor agent in rheumatoid arthritis patients with inadequate response to anti-tumor necrosis factor agents. Arthritis Rheum 2007;56:1417-23. 